\title{
Internato rural na Amazônia: aspectos históricos, contexto atual e principais desafios
}

\author{
Rural internship in the \\ Amazon region: historical \\ aspects, current context and \\ main challenges
}

Rodrigo Pinheiro Silveira

Professor, Curso de Medicina/Universidade Federal do Acre.

BR 364, km 4 - Distrito Industrial

69920-900 - Rio Branco - AC - Brasil

ropsilveira@gmail.com

Roseni Pinheiro

Professora, Instituto de Medicina Social/ Universidade do Estado do Rio de Janeiro.

Rua São Francisco Xavier, 524

20550-900 - Rio de Janeiro - RJ - Brasil

rosenisaude@uol.com.br

Recebido para publicação em abril de 2015.

Aprovado para publicação em setembro de 2015.

http://dx.doi.org/10.1590/S0104-59702017000200004

SILVEIRA, Rodrigo Pinheiro; PINHEIRO, Roseni. Internato rural na Amazônia: aspectos históricos, contexto atual e principais desafios. História, Ciências, Saúde - Manguinhos, Rio de Janeiro, v.24, n.2, abr.-jun. 2017, p.371-390.

Resumo

O artigo faz uma análise histórica de experiências de internato rural na Amazônia, a partir de dados levantados em pesquisa empírica sobre a contribuição dessas experiências para a formação médica na região Norte. Embora influenciadas pelas mesmas ações, as escolas atuais têm desenhos diferentes, revelando cenários heterogêneos dos estágios em municípios e áreas rurais da região amazônica. O internato rural, no entanto, tem proporcionado aos estudantes oportunidades singulares, como atendimento clínico, ações educativas e de saúde, vivências do cotidiano local. São experiências importantes para a formação médica, embora ainda existam desafios para sua consolidação, como logística, preceptoria e modelo pedagógico.

Palavras-chave: internato e residência; saúde da população rural; educação médica; história da medicina.

Abstract

The article conducts a historical analysis of rural internship experiences in the Amazon region, based on data gathered in empirical research on the contribution of these experiences to medical training in the Northern Brazil. Although influenced by the same actions, schools today have different configurations, revealing heterogeneous scenarios for internships in rural municipalities and areas of the Amazon region. Rural internships, however, have given students unique opportunities, such as experience in clinical care, educational and health actions and hands-on experience of local daily life. These are important experiences for medical training, although there are still challenges for its consolidation, such as logistics, mentoring and a pedagogical model.

Keywords: internship and residency; rural health; medical education; history of medicine. 
$\mathrm{O}$ campo da educação médica no Brasil se encontra em processo de transformação. Na década de 1990, o projeto Comissão Interinstitucional Nacional de Avaliação do Ensino Médico reuniu diversas entidades médicas num processo de avaliação das escolas médicas do Brasil que partia do pressuposto de que não estávamos formando médicos de acordo com as necessidades de nossa população. O projeto evidenciou problemas em diferentes dimensões, entre as quais o modelo pedagógico das escolas. A partir desse processo, diversas ações se sucederam no intuito de transformar o modelo pedagógico do ensino médico no Brasil. Entre elas têm papel fundamental as Diretrizes Curriculares Nacionais (DCN) publicadas em 2001, que criaram as possibilidades para a emergência de novas metodologias e novos cenários de ensino e aprendizagem. No bojo desse processo, as experiências de internato rural, que já estavam em curso em algumas universidades, como a Universidade Federal de Minas Gerais e a Universidade Federal do Amazonas, encontraram campo fértil para seu desenvolvimento e fortalecimento. Em 2014, novas DCN foram publicadas garantindo pelo menos 30\% do internato em atenção primária à saúde (APS) e na rede de urgências e emergências, com prioridade para o primeiro. As novas DCN continuam e reforçam as bases político-pedagógicas para o internato rural.

Quando se fala em internato rural, fala-se especificamente sobre os estágios que acontecem em cidades do interior, como parte do período designado como internato médico. O internato é definido como estágio curricular obrigatório de treinamento em serviço (Brasil, 2001), última fase da formação médica em nível de graduação. Os estágios em áreas rurais fazem parte do que a literatura tem designado como rural pipeline (Tesson et al., 2005), que representa um conjunto de ações ligadas ao processo formativo que contribui para o recrutamento de médicos para áreas rurais ou remotas e sua fixação nessas áreas. Além disso, alguns estudos têm explorado seu potencial pedagógico (Barbosa, 1995; Silveira, 2014), notadamente em reflexões sobre o contexto de vida da população brasileira que possibilitam maior aproximação do médico com a realidade daqueles habitantes.

Até meados dos anos 1960, apenas algumas experiências isoladas de extensão universitária tinham o caráter de interiorização das práticas universitárias. Em 1963, houve uma tentativa de aprovar um projeto de lei no Senado Federal que tornaria obrigatória a realização de estágios rurais no último ano dos cursos de medicina. Essa iniciativa não logrou êxito, sendo rejeitada em setembro de 1963. Em 1964, o Brasil passou pelo golpe militar que implantou a ditadura no Estado brasileiro, que duraria 20 anos. Naquela época, membros da União Nacional dos Estudantes eram perseguidos, presos e torturados, e ao mesmo tempo o governo promovia interiorização de ações extensionistas das universidades, com o discurso da integração e do desenvolvimento nacional, por meio do Projeto Rondon. Nessa época, alguns programas localizados já inauguravam a perspectiva de interiorização, como é o caso do Centro Rural de Treinamento e Ação Comunitária (Crutac), criado pela Universidade Federal do Rio Grande do Norte em 1966, que teve como objetivo proporcionar ao estudante universitário uma atuação nas comunidades rurais. O projeto iniciou-se pela saúde, sendo posteriormente expandido para outras áreas e tornando-se uma ação multidisciplinar (Silva, 2013).

Nessa época, houve uma intensa discussão acerca da educação médica e do perfil do médico que o Brasil deveria formar. Setores liberais-privatistas cresceram muito na constituição do sistema de saúde de então, com diversos convênios firmados com o antigo Instituto Nacional 
de Assistência Médica da Previdência Social, Inamps (Brasil, 2007), havendo denúncias de corrupção e apropriações de recursos públicos em prol de interesses particulares. As primeiras experiências de internato rural foram implantadas em meio a essa disputa, teoricamente seguindo na contramão da ideologia médica hegemônica da época, mas se inserindo no contexto de luta pela redemocratização do país, mesmo que não tivesse uma intenção deliberada nesse sentido.

A implantação do internato rural é considerada um avanço nos currículos dos cursos da Amazônia, representando um dos aspectos que privilegiam o olhar regional para a formação em medicina. No processo de análise documental desse trabalho, foram identificados três movimentos que influenciaram e convergiram na construção e no desenvolvimento dessa experiência, que hoje é uma realidade em diversas escolas médicas da região, mas que não é livre de desafios para sua consolidação e seu fortalecimento. O primeiro é o Projeto Rondon, uma das experiências pioneiras da extensão universitária em nosso país, realizada nas décadas de 1970 e 1980, com especial inserção na região Amazônica, com o objetivo principal de integrá-la e protegê-la, o que diz muito a respeito do contexto ideológico vigente nas instâncias governamentais na época da ditadura militar. O segundo é o internato rural da Universidade Federal de Minas Gerais (UFMG), iniciado em 1978, sendo uma das experiências pioneiras na interiorização da graduação no Brasil. Pelo reconhecimento de seu sucesso, influenciou a implantação de estágios curriculares de graduação fora da sede das universidades em diversos cursos de medicina no país. O terceiro é o Projeto Saúde Alegria, sendo uma influência mais recente realizada nas décadas de 1990 e 2000, principalmente por sua característica de trabalhar para desenvolver a tecnologia da atenção à saúde em unidades fluviais. O projeto era realizado no rio Tapajós, Santarém (PA), e trouxe a perspectiva da atenção primária itinerante com utilização da arte na promoção da saúde para as comunidades ribeirinhas da Amazônia.

O presente artigo tem como objetivo caracterizar os marcos históricos do internato rural na Amazônia, contextualizar o momento atual e apontar os desafios para sua consolidação como experiência de ensino-aprendizagem dos cursos de medicina da região. A base para os dados aqui dispostos foi constituída pela revisão bibliográfica, análise documental e pesquisa empírica realizada em 2013 para tese de doutorado sobre internato rural na Amazônia (Silveira, 2014). A metodologia utilizada para a pesquisa empírica se encontra detalhada na referida tese.

\section{O Projeto Rondon}

O Projeto Rondon foi criado em 1968, em plena ditadura militar, a partir do decreto presidencial n.62.927, tendo sido o "primeiro grande programa de extensão universitária de abrangência nacional" e também um dos mais longos, durando mais de 20 anos. O discurso oficial do projeto era convocar a juventude e a universidade a participar do processo de integração nacional, seguindo a lógica nacionalista de ocupação e defesa do território. Seu lema era "integrar para não entregar" (Maciel Filho, Branco, 2008).

A experiência-piloto do projeto foi em Rondônia, numa expedição da Universidade Federal de Santa Maria que reuniu 31 estudantes de diversos cursos; entre eles, o de medicina. Começava aí uma das maiores experiências de interiorização que o Brasil já viveu, defendida 
e criticada por segmentos da sociedade, tendo influenciado diversas ações e talvez gerado consequências não previstas no início do processo. A partir do Projeto Rondon, muitas pessoas tiveram oportunidade de conhecer recantos pouco visíveis do território brasileiro, como é o caso da Amazônia, que foi uma das regiões de maior ênfase no projeto.

As inserções no Projeto Rondon podiam ser feitas de duas maneiras: uma de menor intensidade pelo período de 30 dias, geralmente nas férias; e outra pelo período de seis meses, quando alunos e professores se distanciavam do seu cotidiano acadêmico para uma imersão mais longa em outra realidade do país (Santos, Mendes, 2005). A inserção dos alunos era voluntária, e a proposta era que eles pudessem desenvolver atividades de seu campo de atuação no interior do país, colaborando para o desenvolvimento local. "Os estudantes viveriam e sentiriam em toda a sua chocante realidade a vida no interior do Brasil" (Brasil, 1972, p.8-9; Maciel Filho, Branco, 2008).

Com a gradativa expansão do projeto, foi criada a Fundação Projeto Rondon, para gerenciar o financiamento das expedições e a contratação de profissionais especificamente para o projeto. Houve o crescimento da participação das universidades brasileiras, principalmente do Sul e do Sudeste, constituindo campi avançados nos pontos de menor desenvolvimento do país, notadamente na Amazônia.

O primeiro campus avançado foi o da Universidade Federal de Santa Maria em Boa Vista (RR) (Santos, Mendes, 2005). Nesse movimento, em 1969, a então Universidade do Estado da Guanabara (UEG, atual Universidade do Estado do Rio de Janeiro) implantou o campus avançado de Parintins (AM), e, em 1972, a Universidade Federal Fluminense (UFF) implantou campus em Óbidos, PA, posteriormente transferido para o município vizinho de Oriximiná, onde funciona até hoje (Silva, 2013).

No total, foram implantados 22 campi avançados, a quase totalidade localizada nas regiões Norte, Nordeste e Centro-Oeste (Brasil, 1980). O campus avançado da UEG em Parintins iniciou suas atividades em 1969, por meio de convênio entre a UEG, o Ministério do Interior e a Prefeitura de Parintins. Nele eram realizados os estágios na área da saúde, com grupos de dez internos e cinco estudantes da quarta série de enfermagem em rodízio bimestral, visando ao "atendimento médico sanitário a ser planejado e posto em execução na área municipal de Parintins" (UEG, 8 dez. 1969). As atividades tinham como objetivos:

a) integrar os universitários e a própria atividade universitária na problemática brasileira do desenvolvimento;

b) possibilitar a transferência de recursos humanos das grandes áreas geoeconômicas para a Amazônia, criando e acelerando polos de desenvolvimento;

c) promover estágio de observação e treinamento, objetivando conduzir os jovens alunos da UEG a participar do processo de integração nacional;

d) promover o aperfeiçoamento do ensino tecnológico, médico e socioeconômico, ministrado na UEG, por meio do contato dos diplomandos com a realidade brasileira;

e) permitir aos universitários das diferentes unidades trabalhos em equipe interprofissional (UEG, 8 dez. 1969).

Observa-se que já nessa época aconteciam rodízios de internato na Amazônia, mesmo que não com a alcunha de internato rural, bem como que os objetivos tinham como mote principal 
a participação da universidade e dos jovens estudantes no desenvolvimento e integração do país. Nos últimos dois objetivos, verifica-se que na época eram também valorizadas questões importantes para o internato rural de hoje: o aprendizado a partir do contato com a realidade e o trabalho em equipe multiprofissional.

O campus de Parintins viria a sediar posteriormente a primeira experiência de internato rural na Amazônia, pela antiga Universidade do Amazonas (UA), hoje Universidade Federal do Amazonas (Ufam). Em seu auge, o projeto era robusto em termos de financiamento e estrutura, avançando em incentivos para interiorização de profissionais de nível superior e a criação de um serviço civil social. Em seus 22 anos de existência, o Projeto Rondon envolveu cerca de 350 mil estudantes e 13 mil professores, contemplando grande quantidade de municípios, principalmente nas regiões Norte, Nordeste e Centro-Oeste. Apesar da importância e magnitude, o projeto não ficou livre de críticas, iniciando seu declínio no início dos anos 1980, com o processo de redemocratização, sendo extinto no final de 1989 (Maciel Filho, Branco, 2008).

Durante seminário de avaliação em 1979, o projeto recebeu várias críticas, principalmente relativas ao funcionamento dos campi avançados, que, segundo o Conselho Federal de Educação, operavam como "enclaves culturais", sem comunicação e integração com setores e universidades locais. Houve preocupação também com o tempo curto de permanência do estudante e um possível choque cultural mais profundo, e nem sempre fácil de controlar, que poderia ocorrer. Com o processo de redemocratização, outras críticas de cunho mais ideológico começaram a ganhar força, acusando o projeto de "anestesiar a juventude universitária", que seria uma "forma fascista de mobilização de jovens" e "instrumento da propaganda oficial do autoritarismo" (Maciel Filho, Branco, 2008; Lima, 2012).

Não obstante as críticas, o projeto parece ter representado importante movimento no processo de interiorização e proporcionou o conhecimento de outras realidades por parte de seus atores, o que pode ter tido consequências não previstas e pouco descritas, como inserções mais profundas em comunidades e movimentos sociais, por meio de ações de educação popular. Com isso, pode ter havido um processo de conscientização sobre a realidade do interior e aumento do compromisso social por parte dos estudantes.

Sua extinção pode ter sido motivada também por um movimento simbólico contra a ideologia da ditadura militar, que cerceava o poder de exercer a democracia, o que marcou profundamente a sociedade brasileira. No seu processo de desmantelamento, não houve o cuidado devido com o patrimônio e a estrutura que o projeto constituiu.

Ao ser extinto o Projeto Rondon, não se considerou, também, o desperdício de recursos financeiros que se estava praticando, com a dilaceração de seu espólio, pelo abandono completo, ou cessões improvisadas das instalações e equipamentos dos vinte e três campi avançados (Maciel Filho, Branco, 2008, p.63).

\section{O internato rural da UFMG}

Reconhecido em todo o país como experiência pioneira, o internato rural da UFMG completou 35 anos de existência em 2013. Assim como o Projeto Rondon, surgiu no período da ditadura militar, mas com sua centralidade na prática médica, e não na questão territorial. 
Seu objetivo está mais condizente com a ampliação da atenção para além do modelo biomédico que norteia a prática e o ensino tradicional em hospitais universitários, abordando de maneira privilegiada as relações entre medicina e sociedade (Barbosa, 1995). Embora esse seja o mote principal, as questões políticas sempre permearam (nem sempre explicitamente) o propósito de desenvolver a iniciativa de levar os estudantes para o interior. Barbosa (1995, p.23) aponta que uma das questões era

buscar uma ruptura entre o aluno e sua concepção elitizada da medicina e proporcionarlhe um outro espaço que possibilitasse vivenciar um conjunto de relações que envolvesse a população como aprendizado, e ainda permitisse, no mínimo, uma reflexão sobre esse processo.

A proposta surgiu no início dos debates sobre as transformações da educação médica no Brasil, contribuindo para as reflexões e ações sobre a diversificação dos cenários de aprendizagem e a integração ensino/serviço. Por sua característica e seu objetivo, tratava-se de uma proposta contra-hegemônica na época, no sentido de uma aproximação crítica à realidade do país, em um momento delicado que nossa sociedade vivia.

No momento em que o país vivia um processo de cerceamento das liberdades democráticas e institucionais, a Faculdade de Medicina da UFMG realizou uma abertura do processo acadêmico, promovendo através da integração docente-assistencial a aproximação e interação do pensamento acadêmico com os movimentos sociais e com a realidade social e de saúde das comunidades para além do que era propagado pelos meios de comunicação e pela versão oficial imposta pelos governos militares (Polignano et al., 2004, p.2).

O início das experiências embrionárias da UFMG na área rural se deu no Vale do Jequitinhonha no início dos anos 1970, com expedições voluntárias de estudantes de medicina. Com o impacto das primeiras vivências, houve um movimento de alunos e professores que culminou na proposta curricular do internato rural, finalmente efetivada em 1978. Durante os anos 1980 e 1990, o estágio se expandiu para outras regiões do estado de Minas Gerais e para outras áreas da saúde, como odontologia, enfermagem e farmácia, embora ainda hoje não seja realizado de maneira integrada. O objetivo geral do internato rural da UFMG é:

Propiciar aos estudantes a oportunidade de melhor apreenderem as relações entre medicina e Sociedade através da participação direta no SUS e nos movimentos sociais, dentro da perspectiva de consolidar uma proposta de integração docente-assistencial, contribuindo para a formação de um profissional capaz de responder às necessidades assistenciais, de prevenção e promoção de saúde da população, exercendo na sua plenitude o papel social de cidadania (Polignano et al., 2004, p.1).

Atualmente, mais de dez mil alunos já passaram pelo internato rural, em mais de 30 municípios do interior de Minas Gerais, a maioria com menos de 20 mil habitantes (Polignano et al., 2004).

Guimarães (2004) ressalta que o internato rural desperta consciência crítica no futuro médico, permite que ele avalie seu aprendizado na graduação, com base na aplicação de seus conhecimentos conforme as demandas locais em saúde, além de proporcionar uma reflexão sobre a organização do sistema de saúde. O autor chama a atenção para o fato de que no 
internato rural o aluno já assume o papel de médico, e o contato com a realidade o faz refletir sobre o processo saúde/doença e o papel do médico na sociedade.

Essa perspectiva é confirmada pelas falas de um estudante da UFMG citadas por Polignano et al. (2004, p.5-6), em que os aspectos relacionados à valorização do estudante já como "doutor", trazendo à tona a responsabilidade frente a uma "crença humilde" dos usuários, fazem com que os alunos estejam atentos à questão da escuta e da linguagem, bem como da atitude humilde, humanizada e politizada frente à realidade, vivenciada de maneira intensa pelo interno.

O caráter de experiência de vida, de amadurecimento e compromisso está presente no relatório de um seminário de avaliação realizado em 2004, de onde destacamos as seguintes passagens, que nos ajudam a ter a verdadeira dimensão da importância do internato rural para a formação de atitudes dos estudantes de medicina:

A disciplina de Internato Rural da Faculdade de Medicina da UFMG constitui uma experiência única no sentido de complementação da formação profissional, humana e política do futuro médico ... O estilo de vida nas pequenas comunidades rurais é muito diferente do cotidiano de um grande centro ... E mesmo para os mais experimentados existem dificuldades em se inserir nesse cenário ... O Internato Rural emoldura a concepção de promoção de saúde como prioridade e nos faz acrescentá-la em nossa formação profissional. Nos insere em uma localidade e nos faz adotar uma posição ativa diante de seus problemas, qualquer que seja a maneira que encontrarmos para atuar (Polignano et al., 2004, p.5-6).

De fato, essa experiência se mostrou um diferencial no currículo da UFMG e é considerada uma das ações pioneiras de integração entre ensino, pesquisa e extensão da universidade (Abreu et al., 2009). Não é por acaso que diversas escolas médicas de todo o país se espelharam na experiência da UFMG para criar suas próprias propostas, responsáveis por outros e distintos resultados, que passam a ser explanados a seguir.

\section{Projeto Saúde e Alegria ${ }^{1}$}

No final dos anos 1980, um grupo de médicos do Sudeste do país começou um trabalho de assistência e promoção da saúde na área ribeirinha do rio Tapajós, na região de Santarém (PA). Com o crescimento do trabalho, que agregou também artistas, eles fundaram uma organização não governamental chamada Saúde e Alegria e receberam financiamento do Banco Nacional do Desenvolvimento (BNDES), o que permitiu que fossem criadas pequenas estruturas (postos de saúde) nas comunidades para desenvolver o projeto. Esse crescimento inicial e as ideias pioneiras dos participantes possibilitaram a assinatura de um convênio de trabalho com a ONG holandesa Terre des Hommes, viabilizando a construção de uma unidade de saúde fluvial, o barco Abaré.

A partir do final da década de 1990 e na primeira década deste século, a equipe do Saúde e Alegria fez inúmeras expedições pelo rio Tapajós, realizando ações de assistência, na perspectiva da atenção primária e de promoção da saúde, por meio da arte, nas comunidades ribeirinhas. Ao longo desse caminho, alunos e professores de mais de vinte universidades tiveram a oportunidade de participar de vivências no Abaré. 
Nessa época, o Saúde e Alegria e a Unidade Fluvial Abaré ganharam notoriedade nacional, iniciando um processo de transferência de tecnologia para o poder público e influenciando os debates mais recentes sobre a organização da atenção à saúde da população ribeirinha da Amazônia. Com a possibilidade de expansão, foi construída a Unidade Fluvial Abaré II, que passou a atuar no rio Arapiúns, também na região do baixo Amazonas. Essa segunda unidade fluvial foi repassada para a prefeitura de Santarém e hoje abriga uma das equipes rurais de Saúde da Família do município.

Com a crise econômica da Europa no final da primeira década dos anos 2000, a contribuição da ONG holandesa foi progressivamente diminuindo, causando impacto nas ações do Saúde e Alegria, com expressiva redução dos participantes do projeto. Atualmente, o barco Abaré realiza um número reduzido de ações, e está em discussão o destino que se dará à unidade fluvial, havendo proposta de parceria com a Universidade Estadual do Pará (Uepa), incorporando-a às ações do internato rural do curso de medicina de Santarém, com a possibilidade da participação de outras universidades interessadas.

A tecnologia utilizada no Abaré e no Abaré II foi recentemente utilizada pelo Ministério da Saúde para a padronização de unidades fluviais para a Amazônia. Foram construídas várias dessas embarcações para a atenção à saúde rural nos municípios da região. A Unidade Igaraçu, do município de Borba (AM) foi a primeira a ser implantada na nova política de atenção à saúde da população ribeirinha e foi incorporada à atual Política Nacional da Atenção Básica do Ministério da Saúde (Brasil, 2012).

\section{A implantação do internato rural na Amazônia}

Na segunda metade dos anos 1980, o Projeto Rondon já estava em declínio, mas muitas universidades permaneciam com seu campus avançado em atividade, como era o caso da Uerj em Parintins. Nessa época, a proposta era que houvesse criação de expertise local a partir de parcerias de universidades do Sul e Sudeste com universidades locais. Em um encontro de professores da Uerj com professores da Universidade do Amazonas (UA), houve uma provocação para que as universidades locais implantassem estágios no interior do estado (Silveira, 2014).

Dessa provocação, iniciou-se um processo de discussão entre professores e alunos da UA na construção das bases de um estágio rural. Como naquela época a referência no Brasil era o trabalho que a UFMG desenvolvia no Vale do Jequitinhonha, uma comitiva da UA foi conhecer o trabalho lá desenvolvido. Na volta, houve uma série de assembleias lideradas pelo professor Mena Barreto para a construção da proposta de internato rural para o curso de medicina da UA.

No decorrer do processo, já estava sendo desenvolvida em Parintins uma disciplina optativa chamada "Medicina rural", embrião do internato rural, em que os alunos tinham a sua base no campus da Uerj em conjunto com os alunos daquela universidade. Essa inserção em Parintins no contexto de declínio do Projeto Rondon permitiu que se fizessem assembleias no próprio município, culminando na decisão, com participação da comunidade local, da transferência do campus da Uerj para a UA (Silveira, 2014). 
Com a oficialização do campus, em 1988, teve início o internato experimental, com a ida de um grupo da UA. Esse início não foi livre de resistência, principalmente das famílias dos estudantes de Manaus que tinham receio da ida de seus filhos para cidades pequenas. Com os professores, apesar da controvérsia de sua importância para a formação médica, a negociação fluiu melhor, desde que não interferisse com aqueles que não desejavam acompanhar os alunos nas pequenas cidades. O grupo de professores e alunos liderados pelo professor Mena Barreto e pela professora Eliane Feijó construíram a resolução sobre o internato rural da UA, que foi aprovada pelo colegiado de curso e possibilitou a oficialização do estágio (Universidade do Amazonas, 1991).

Com o sucesso do trabalho desse primeiro grupo e as bases legais aprovadas, em janeiro de 1989 iniciou-se a primeira experiência oficial de internato rural na Amazônia, na cidade de Parintins. As ações tinham apoio da fundação Serviço Especial de Saúde Pública (Sesp), que mantinha um hospital e uma unidade de lotação no município, contando também com visitadoras sanitárias e auxiliares de saneamento. Os alunos se inseriam nas ações de assistência e promoção, permanecendo de três a quatro meses no município sob supervisão de profissionais da região e professores da universidade. Incorporados naquela realidade, poderiam refletir sobre os determinantes de saúde e entrar em contato com problemas locais, além de contribuir para o desenvolvimento do sistema de saúde no interior, que, à época, ainda enfrentava dificuldades significativas.

A partir dessa primeira experiência, os rodízios do internato rural ocorreram de maneira ininterrupta em Parintins e, ao longo do tempo, outros municípios foram incluídos no processo, havendo hoje uma quantidade expressiva de municípios do Amazonas em que ocorre o internato rural da Ufam. A resolução aprovada pelo colegiado, regulamentando o estágio, influiu na implantação do estágio rural da Universidade do Estado do Amazonas (UEA) e de outros cursos de medicina que foram sendo inseridos nos anos 2000, no contexto de expansão de escolas na região Norte do país.

\section{Concepção pedagógica e atividades realizadas no internato rural}

Um dos únicos estudos que tratam especificamente sobre a questão das concepções pedagógicas do internato rural no Brasil é o realizado como dissertação de mestrado por Barbosa (1995) sobre a experiência da UFMG. A autora contextualiza a disciplina no movimento de transformação da educação médica, considerando a emergência de um novo paradigma na saúde, que considera o homem inserido na sociedade, e as mudanças nos modelos assistenciais, com ampliação e maior ênfase na atenção primária à saúde. Dessa maneira, ela situa o internato rural como um rompimento com a perspectiva hospitalocêntrica da educação médica, deslocando o eixo do aprendizado para os cuidados primários, focalizando os agravos mais comuns da população, considerando prevenção e assistência, observando o ser humano integrado à sociedade.

De acordo com as reflexões da autora, a concepção pedagógica do internato rural não considera o ensino mera reprodução do saber, centrado nas questões de aprendizado próprias do domínio cognitivo, mas privilegia o aprender fazendo, possibilitando a manifestação da 
criatividade do estudante. De fato, a relação ensino/aprendizagem presente no internato rural se concretiza na experiência. John Dewey (2010) ensina que não é qualquer experiência que nos traz aprendizado. Para ele "tudo depende da qualidade da experiência que se tem" (p.28). E essa qualidade leva em consideração dois aspectos: ser agradável ou desagradável e ser capaz ou não de influenciar experiências posteriores. Se, para o autor, o primeiro é fácil de julgar, o segundo requer níveis mais profundos de análise.

O efeito de uma experiência não se origina em sua superfície e isso se torna um problema para o educador. É sua tarefa proporcionar situações para que as experiências, embora não provoquem resistência por parte do aluno, mobilizem seus esforços e que, além disso, se apresentem em forma de atividades mais do que imediatamente agradáveis, na medida em que o estimulem e o preparem para experiências futuras. Assim como nenhum homem vive e morre para si mesmo, nenhuma experiência vive e morre para si mesma (Dewey, 2010, p.28).

A partir dessa consideração, é de importância pedagógica para o internato rural que seus coordenadores e professores atuem para que a experiência seja positiva e que as questões que emergem da experiência para reflexão façam sentido para a prática médica futura. Barbosa (1995) ressalta que nem todas as experiências do internato rural da UFMG foram positivas, lembrando situações em que estudantes permaneceram em pequenos municípios sem médicos como preceptores e com mínimas condições de trabalho. Assim, a experiência que pretende ser positiva e marcante como ação de aprendizagem pode se tornar estressante e traumática para o estudante.

O desenvolvimento da responsabilidade e da autonomia do estudante é questão central para o internato rural. Trata-se de "uma antecipação, ainda que sob supervisão, do momento no qual ele faria a ruptura definitiva do seu vínculo com a Universidade" (Barbosa, 1995, p.24-25). Nessa perspectiva, o professor é um facilitador e atua mais na supervisão (presencial e a distância) das ações, debatendo as questões mais importantes que se colocam ao longo da experiência, tanto em relação à resolução ou enfrentamento de problemas quanto nas reflexões sobre a prática que o estudante exercita frente a realidade vivida, e aponta caminhos para o desenvolvimento integral do futuro médico. Na cidade pequena, o acompanhamento cotidiano se dá por profissionais que atuam no local como preceptores a quem os estudantes recorrem de maneira mais imediata em caso de dúvidas.

A centralidade no estudante como elemento pedagógico fundamental do internato rural permite que o próprio possa interferir ativamente em seu itinerário formativo, reconhecendo e procurando preencher lacunas existentes num processo de autoavaliação, e procurando construir sua própria forma de exercer a medicina. Além disso, ele pode atuar como sujeito social, apontando e procurando enfrentar conjuntamente as demandas e necessidades das pessoas do interior. Dessa forma, pode também despertar para a realidade social e de saúde da população, identificando a estreita relação entre as duas. "A proposta pedagógica pretendia, com a utilização de dados da própria realidade social, desfazer o mito de que a academia de medicina vivia em uma 'torre de marfim'” (Barbosa, 1995, p.27).

Os estudantes geralmente são recebidos na Secretaria Municipal de Saúde e inseridos em uma das Unidades Básicas de Saúde junto a uma ou mais equipes de Saúde da Família. A partir das orientações dos preceptores ou junto com eles, os estudantes constroem uma rotina de 
atividades e um cronograma de ações, que seguem também a programação de atividades da equipe para o período de estágio.

As atividades mais descritas pelos estudantes são as consultas médicas e as ações de educação em saúde. Nas consultas, eles atuam sozinhos ou acompanhando o preceptor. No primeiro caso, é comum eles discutirem a conduta com o preceptor antes de finalizar com o paciente. Ao longo do internato, com a rotina de atendimentos, os estudantes vão observando e refletindo sobre sua prática. Costumam ficar muito entusiasmados com a reação das pessoas à sua abordagem, em que são chamados de "doutor", com a gratidão e a valorização de sua atitude como médico. Eles referem que aos poucos vão conformando uma maneira própria de atender e que o fato de estarem mais "sozinhos" faz com que desenvolvam um estilo próprio de praticar a medicina (Silveira, 2014).

As atividades de educação em saúde são realizadas nos serviços, escolas, centros comunitários e outros dispositivos locais. Seguem geralmente a programação das equipes conforme a época de campanhas ou a partir do atendimento de número expressivo de determinado problema. São feitas atividades com temas como tuberculose, higiene, violência, acidentes de motocicleta, doenças crônicas etc. Um dispositivo que na maioria das cidades os estudantes têm a oportunidade de vivenciar é a rádio local. Eles participam ativamente dos programas de rádio, tendo a chance de planejá-los e executá-los, sentindo o retorno da população local em relação às questões abordadas nessas ocasiões.

A vivência de trabalho em equipe parece ser diferenciada no internato rural. Devido ao fato de estar inseridos em uma equipe integralmente, eles participam das reuniões e de todo o processo de planejamento e execução das atividades. Esse cotidiano mais intenso de vivência de equipe parece trazer maior valorização dos profissionais das diferentes áreas e das funções desempenhadas. Trata-se de uma experiência importante num contexto de corporativismo profissional em que se vive atualmente, podendo trazer frutos para as possíveis inserções em equipe após o tempo de seu curso. Embora seja uma realidade em algumas localidades, essa vivência é dependente da dinâmica das equipes locais com as quais os estudantes têm contato, não sendo uma característica intrínseca da experiência.

Os atendimentos realizados na zona rural, em vilas e pequenos povoados, são muito valorizados pelos estudantes que fazem o internato rural. É sobre as ações nessas localidades que eles fazem relatos mais intensos e mobilizadores de afeto (Silveira, 2014). A oportunidade de participar de uma ação em unidade fluvial é ímpar na vida do estudante, pois ele fica dias imerso na experiência de visitas às comunidades ribeirinhas e no trabalho e na convivência em equipe. Ao mesmo tempo que conhece uma nova realidade, contribui para a melhoria da saúde de pessoas que têm pouco acesso a cuidados de saúde em seu cotidiano. Essa experiência, quando positiva, é gratificante para o estudante, que sente que, enquanto aprende a ser médico, contribui para a melhoria da saúde daquela população. Os atendimentos em área rural dão maior dimensão às questões do contexto de vida, da realidade familiar e social, e da cultura das pessoas, sendo uma das ações em que mais aproveitam seu processo de aprendizado com a experiência.

A experiência do internato rural não se limita às atividades de saúde que desempenham. Desde o momento em que os estudantes saem de suas casas, percebem um mundo novo, em que permanecem em convívio diário com um grupo que às vezes nem conheciam. 
São levados a se organizar como pessoas, em sua alimentação, limpeza das roupas e organização do tempo. Nos momentos de lazer, têm a oportunidade de conhecer lugares e pessoas, de se divertir em um contexto a que não estavam acostumados e de trocar ideias e ouvir histórias que não ouviriam na capital. Trata-se não apenas de uma experiência acadêmica, mas de uma experiência de vida.

Sob o ponto de vista da proposta pedagógica, o Internato Rural representa a oportunidade de propiciar ao aluno a vivência de fato e a consequente reflexão sobre a realidade diversificada do trabalho médico, possibilitando-lhe exercer um papel importante de ator e não somente de espectador passivo, resultando disso uma graduação integrada socialmente. Essa oportunidade de participar do cotidiano popular, de suas dificuldades, suas estratégias de sobrevivência, seus mecanismos políticos e de poder dos grupos comunitários representa um aporte pedagógico inesgotável (Barbosa, 1995, p.25).

\section{Contexto atual do internato rural na Amazônia}

O internato rural não constitui uma ação isolada no currículo de medicina. Os princípios de sua realização são congruentes com as transformações do ensino médico no Brasil, que vêm acontecendo nas últimas duas décadas e que têm como marco referencial as DCN para os cursos de medicina, publicadas em 2001 e atualizadas em 2014 (Brasil, 2001, 2014).

A constatação de uma prática médica que não é capaz de gerar respostas satisfatórias para as necessidades da população e do sistema de saúde foi a principal motivação para que o processo de transformação se iniciasse. A formação com ênfase na técnica e no estudo das doenças acaba por deixar em segundo plano a pessoa (o paciente). Os médicos se concentram então em diagnosticar e tratar doenças, mas não se dão conta de que esse processo de adoecimento é vivido por uma pessoa, que pouco é entendida em sua integralidade pelo profissional. Há então, como nos ensina Ayres (2007), um distanciamento entre a eficácia técnica, ou seja, o saber fazer na perspectiva médica (conhecimentos e procedimentos), e o sucesso prático, que depende da vida e das ideias dos pacientes sobre o processo de adoecimento. As questões centrais da origem desse distanciamento se encontram no paradigma biomédico (biomedicina) da prática e na formação médica, sendo bastante amplificado pela perspectiva mercantilista da profissão com ênfase nas especialidades, muito intensa e enraizada atualmente na sociedade, e que está atrelada à atuação de indústrias farmacêuticas e de equipamentos no campo da medicina.

O movimento de transformação da formação médica tem como objetivo preparar um médico crítico e reflexivo, que conheça o sistema de saúde em que vai atuar e que tenha compromisso social e atitude baseados no respeito, na ética e nas necessidades da população. Para a formação desse médico, algumas mudanças no currículo têm sido incorporadas, entre elas, a mudança do modelo pedagógico, passando da centralidade do professor para o protagonismo do aluno no aprendizado, e a diversificação dos cenários de prática, com a inserção dos alunos na atenção primária desde o início do curso e as iniciativas de internato rural. 
A expansão da educação médica na região Norte do Brasil é um fenômeno recente. Como observado no Gráfico 1, até o ano 2000 só existiam cinco escolas médicas na região. A partir da virada do século, houve um aumento importante do número de cursos de medicina, chegando atualmente a 22 escolas (Brasil, 2015). As 17 escolas que iniciaram suas atividades após 2000, na vigência das DCN, já incorporaram em maior ou menor grau as mudanças curriculares que teoricamente podem contribuir para a formação de um médico mais próximo das necessidades do sistema e da população. Sendo assim, a quase totalidade dessas escolas tem em seu currículo a previsão de períodos de estágio ou internato rural.

Gráfico 1: Expansão dos cursos de medicina na região Norte

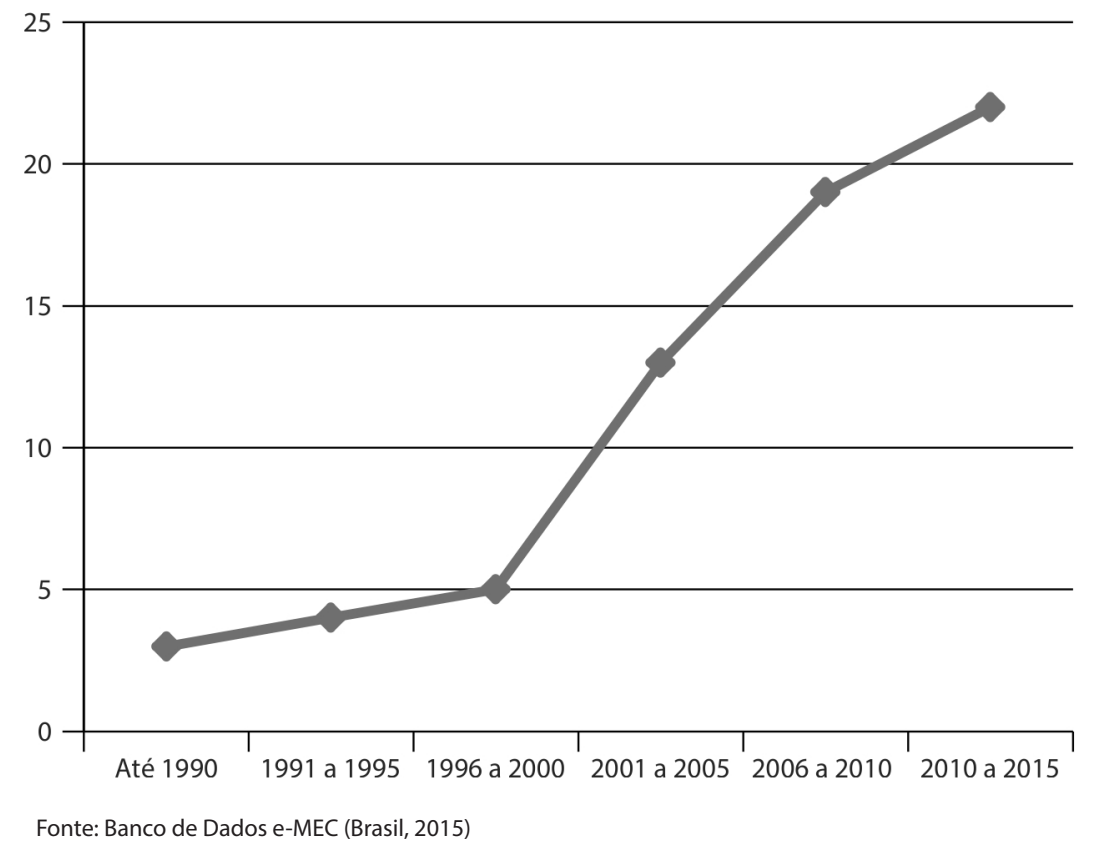

O internato rural, considerando possíveis flutuações relacionadas à conjuntura local, está presente atualmente em cerca de 42 municípios da região Norte (Figura 1), a maioria dos quais com até 50 mil habitantes. Trata-se de municípios que, em grande parte, possuem área territorial extensa, mas cuja sede está incrustada no interior da floresta e geralmente é banhada por um dos rios da região. Os alunos utilizam os mais variados meios de transporte para chegar ao município: via aérea para locais mais distantes, por exemplo, Tabatinga (AM); fluvial para os de distância mediana, por exemplo, Borba (AM) e Juruti (PA); e terrestre para os mais próximos, por exemplo, Iranduba (AM) e Santa Bárbara (PA).

Nas experiências de internato rural na Amazônia, o grupo de alunos faz uma imersão na realidade do município, permanecendo um tempo que varia três semanas e a quatro meses, normalmente sem interrupções. Nos programas mais estruturados, os alunos recebem uma bolsa, que pode chegar a dois salários mínimos, paga pela universidade ou pelo município, sendo este último geralmente responsável pela hospedagem dos alunos, em casa alugada, pousada ou hotel. 
Em algumas experiências, como a da Universidade do Estado do Amazonas (UEA) e da Universidade Federal do Tocantins (UFT), são formadas equipes multidisciplinares para a realização do estágio rural com integração de alunos de medicina, enfermagem e odontologia. Essa característica pode contribuir para a diminuição das tensões existentes entre as profissões, muitas vezes desde a universidade. Embora sendo o ambiente propício para promover interface entre os cursos, a maioria das universidades não a realiza, permanecendo somente os estágios na área médica ou em outros cursos de maneira independente.

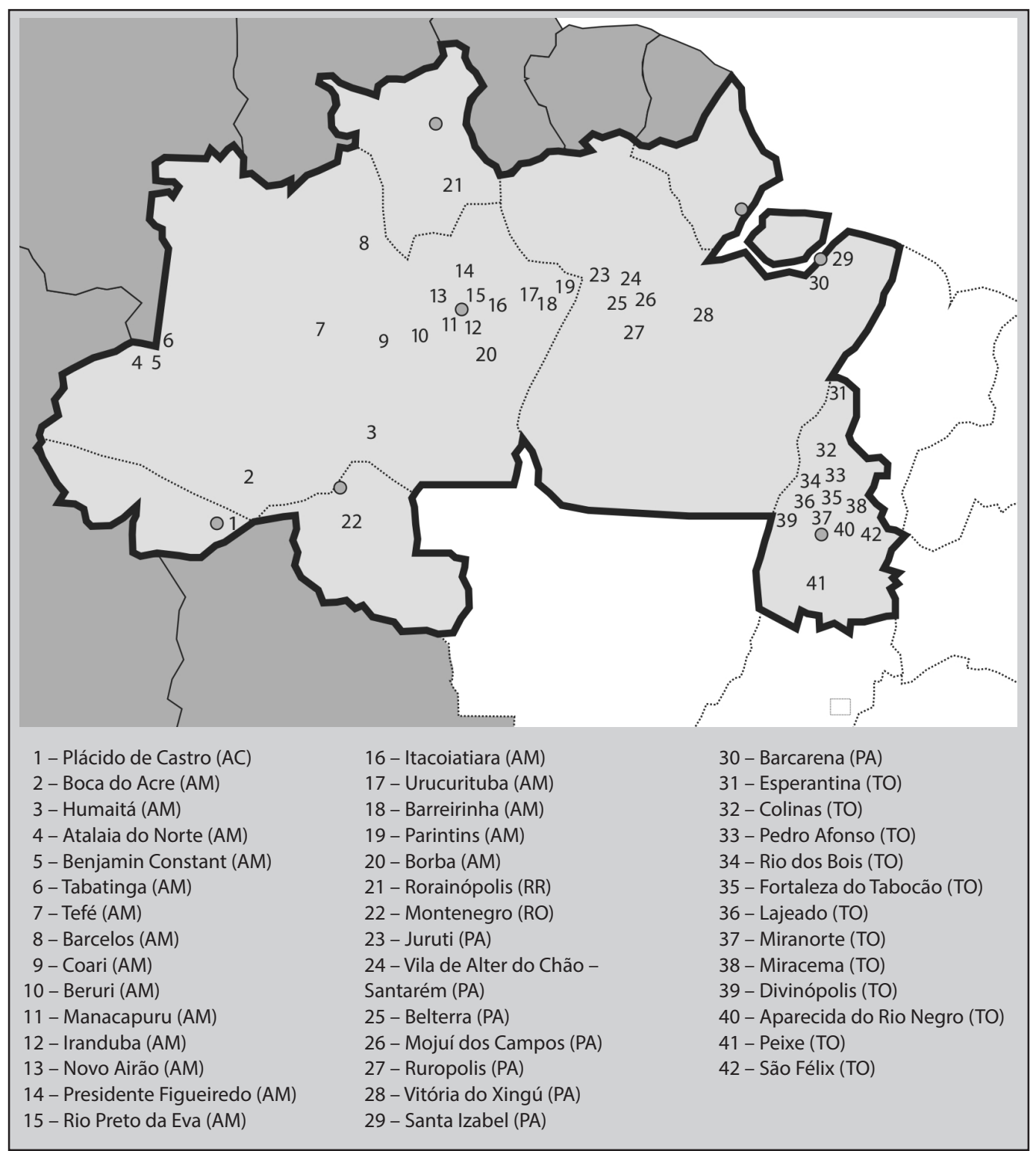

Figura 1: Municípios que contam com internato rural na Amazônia, 2013 (Silveira, 2014) 
As experiências de internato rural na Amazônia têm diferentes características de realização e estão em diferentes estágios de implantação. Existem universidades que têm experiências mais antigas e consolidadas, como a Ufam, e aquelas que são relativamente novas e que caminham para a consolidação, casos da UEA e Uepa-Santarém. Essas contam com um número expressivo de municípios conveniados e com resultados mais consistentes dos estágios. Há outras que ainda buscam se firmar, como a Universidade Federal do Acre (Ufac) e a Universidade Federal do Pará (Ufpa), com número reduzido de municípios conveniados e muito dependente da ação dos professores. Há ainda aquelas que estão no início, mas começaram com grande apoio, como a UFT, e também aquelas que estão inativas, como é o caso da Universidade Federal de Rondônia (Unir) e Universidade Federal de Roraima (UFRR).

Alguns cursos de medicina de instituições privadas da região também desenvolvem o internato rural, como é o caso da Faculdade São Lucas (RO), que faz o estágio no município de Montenegro (RO), em convênio com a Universidade de São Paulo, que possui um campus de pesquisa na localidade. A partir de informações básicas dos cursos médicos, é possível identificar três situações em que as experiências de internato rural se encontram atualmente na Amazônia: (1) experiências incipientes em um município do interior; (2) experiências ativas em um município do interior; e (3) experiências ativas em mais de um município do interior. Das escolas estudadas na fase exploratória e no trabalho de campo propriamente dito, quatro já estão na desejada situação 3 (Ufam, UEA, Uepa-Santarém e UFT); quatro se encontram na situação 2 (UFPA, Centro de Ensino Superior do Pará, e Faculdade São Lucas (RO), Faculdade Nilton Lins (AM); e cinco ainda estão tentando consolidação, permanecendo na situação 1 (Ufac, UFRR, Unir, Faculdade de Ciências Biomédicas de Cacoal (RO), Faculdades Integradas Aparício Carvalho (RO). Esses dados reforçam a dificuldade de consolidação do internato rural na região, havendo necessidade de produção de conhecimento e ações concretas para apoiar as iniciativas das escolas (Silveira, 2014).

\section{Desafios para o internato rural na Amazônia}

Embora a importância do internato rural seja atualmente reconhecida por professores e alunos como uma atividade diferenciada em seus itinerários formativos, sua consolidação está longe de ser um fenômeno simples. Ainda são consideráveis os desafios que as universidades enfrentam para que essa atividade se concretize, envolvendo questões de diferentes esferas, como as burocráticas, logísticas, pedagógicas, entre outras.

O primeiro desafio é a regulamentação ou inclusão do internato rural nos Conselhos Administrativos das Universidades e/ou Escolas Médicas. A regulamentação constitui um dispositivo importante para deixar claras as regras de estágio, que dizem respeito ao período (tempo), localidade, preceptoria e outros itens tanto logísticos como pedagógicos. Além disso, delimita as situações em que, em caráter excepcional, o estudante possa cumprir o estágio na capital, como no caso de alunas grávidas, nutrizes ou com crianças pequenas. Uma questão com que as universidades têm se deparado é a adequação do internato rural à lei do estágio (Brasil, 2008), que estipula que a instituição deve garantir seguro ao aluno enquanto estiver em campo. Sendo esses locais muitas vezes distantes das capitais, há menor governabilidade das universidades sobre os serviços e as atividades executadas pelos internos, as quais podem, 
de certa forma, tornar os alunos mais vulneráveis a agravos ou condições que afetem sua saúde nesse período.

O internato rural pressupõe articulação entre as universidades e os municípios do interior, que geralmente acontece por meio de convênio firmado entre as duas partes, contemplando as questões envolvidas no bem-estar dos estudantes e nas atividades que eles deverão desempenhar ao longo do estágio. O grande desafio dessa articulação está nos períodos de troca de gestão municipal, que invariavelmente implicam reapresentação da importância do internato rural para o município e para a formação médica, chegando até a possibilidade de renegociação de convênio ou, em situações mais extremas, de descontinuidade do estágio.

Como atividade fora da sede da universidade, a viabilização do internato depende de questões logísticas que não são fáceis de equacionar. O contexto das longas distâncias e de dificuldades relativas a transporte na Amazônia as torna ainda mais desafiadoras. A primeira questão é: como levar os estudantes até os municípios? As distâncias e o acesso guiam as possibilidades. Enquanto há localidades mais próximas das capitais, cujo transporte terrestre é viável, existem muitas outras em que apenas o transporte fluvial ou aéreo é possível, sendo que o porte do município e a largura do rio que o banha condicionam o tamanho do barco ou avião que conseguem chegar a sua sede. Em casos extremos, há municípios em que o rio sofre variação importante do nível conforme a época do ano, impedindo que barcos maiores adentrem seu leito, sendo necessárias pequenas embarcações, como as chamadas "voadeiras". Da mesma forma, as condições da pista de pouso condicionam o tipo de avião, não sendo rara a necessidade de que seja um mono ou bimotor no caso dos pequenos municípios.

Em algumas universidades, o internato rural é realizado numa localidade mais próxima da capital, com acesso terrestre ou fluvial em poucas horas. Nesse caso, geralmente os estudantes podem ir e voltar no mesmo dia para a cidade-sede da universidade. No caso dos programas que acontecem em vários municípios, a moradia e a alimentação para a manutenção dos internos em campo de estágio geralmente são garantidas pelas prefeituras, numa contrapartida dos municípios ao trabalho realizado.

Como já dito, em alguns programas, os internos ganham bolsa de estudos que pode ajudar nas questões logísticas relativas à sua presença no município e pode ser paga pela universidade, pelo município ou por alguma instituição parceira de uma ou de outra parte do convênio. O alojamento costuma ser num hotel ou pousada do local, numa casa alugada, ou até mesmo na casa de algum morador local que se disponha a receber os estudantes.

A preceptoria constitui um dos mais importantes desafios do internato rural, em se tratando das questões pedagógicas e de organização do trabalho local. Os tipos de preceptoria são variáveis conforme a escola médica a que pertence o programa e acabam por influenciar o tipo de atividade que predomina durante o estágio. Em alguns casos, o preceptor é o médico do serviço, predominando como atividades as consultas na unidade sob supervisão direta. Em outros, o estágio é mais centrado nas atividades de saúde coletiva, como educação em saúde e trabalho no território. Nesses casos, o preceptor atua mais como um facilitador do desenvolvimento das atividades locais, sendo um profissional (não necessariamente médico) de algum serviço ou setor da Secretaria de Saúde. A remuneração e o reconhecimento do preceptor não são padronizados, sendo (ou não) realizados a partir das condições da universidade e 
dos municípios. Há casos em que apenas há a emissão de um certificado pela universidade, e outros em que o profissional ganha uma gratificação por sua atividade como preceptor. A regulamentação da atividade de preceptoria é cada vez mais necessária a partir da integração das escolas médicas com os serviços e tem sido objeto de estudos que visam construir as bases para o fortalecimento dessa atividade (Soares et al., 2013).

São incomuns, mas ainda existem, as situações em que o estudante fica sem preceptoria médica local pela falta momentânea de médicos no município. Essa situação constitui um sério problema ético para o estágio, resultando na descontinuidade das atividades de assistência ou até mesmo na retirada dos estudantes do local. Barbosa (1995), tratando da experiência da UFMG, relata que alguns municípios deixavam de contratar médicos por contar com a presença de estudantes do internato rural atuando no lugar dos médicos.

Uma preceptoria forte é importante para dar segurança e guiar o estudante no seu aprendizado, mesmo que o estágio no internato rural tenha como um de seus objetivos fazer com que o estudante ganhe autonomia e capacidade de autogerenciamento. Nas condutas médicas, o preceptor é condição sine qua non, pois é quem confere respaldo legal e dá segurança às escolhas, ainda que não tenha que alterá-las em nada. Além disso, dependendo de suas características, o preceptor pode apresentar o mundo para o estudante, problematizando sua história e construção. A ação no contexto do internato rural na Amazônia pode levar o estudante a reflexões importantes e oportunas sobre o mundo, sua profissão e sua atitude frente aos dois, principalmente ao se relacionar com os pacientes que atende. Trata-se de um momento em que a experiência de vivenciar uma nova realidade e o contato com pessoas que pensam de maneira diferente podem mobilizar valores internos capazes de afetar sua atuação no mundo, e, por conseguinte, influenciar de alguma maneira sua forma de praticar a medicina. Exemplo disso são alguns estudos sobre o recrutamento e a fixação de médicos em áreas rurais (Rourke et al., 2005), que mostram que uma experiência positiva no internato rural pode aumentar a chance de esse egresso trabalhar no interior.

Outro grande desafio para o internato rural na Amazônia é a preparação e a problematização do diálogo entre culturas que ocorre no contato do estudante com a população local, sendo a competência cultural um dos atributos importantes do profissional que trabalha na atenção primária nesse contexto (Targa, 2010). Na área rural da Amazônia, a diferença de vida e cultura entre médico e paciente toma contornos consideráveis, tornando-se uma das questões centrais nesse encontro. As origens do povo, com forte influência dos traços indígenas, sua linguagem, o tempo e a forma como entendem e lidam com o processo de adoecimento podem ser muito diferentes. Já o estudante chega nesse ambiente com uma forte bagagem biomédica dos praticamente seis anos de faculdade, com base em condutas padronizadas em realidades predominantemente hospitalares de grande centro. Pode haver nesse encontro o que os estudantes chamam de "choque de realidade" ou "choque de cultura", referindo-se à diferença que percebem nesse contexto em relação ao seu de origem. Trata-se então de um momento em que idealmente os professores e preceptores, e possivelmente profissionais de outras áreas (como antropologia, sociologia...), devem problematizar essas questões reconhecendo in loco a importância para uma prática da medicina mais próxima da realidade da população.

Entendendo o internato rural como uma experiência cujo aprendizado mais significativo não é propriamente o do domínio cognitivo, mas que o integra com o aprendizado de habi- 
lidades e de atitudes ligadas ao contexto vivenciado, um desafio interessante que se coloca é como avaliar adequadamente esse aprendizado. Geralmente, ao final do estágio, além dos itens ligados a frequência, pontualidade etc. avaliados pelo preceptor, em alguns casos, os estudantes entregam um relatório e fazem uma apresentação para a turma sobre as atividades realizadas. Tradicionalmente, tem-se dificuldade em realizar avaliações que não sejam as provas com questões objetivas ou discursivas que avaliam sobretudo o conhecimento do estudante.

Um dos métodos promissores de avaliação formativa é o portfólio reflexivo (Silva, Francisco, 2009), que pode ser bem aplicado ao contexto de internato rural, pois é capaz de dar a dimensão da experiência nas reflexões que o estudante expressa, podendo ser realizado como uma espécie de "diário de bordo" da experiência.

Um último desafio que trazemos para este texto diz respeito aos benefícios que o internato rural traz para a localidade. No trabalho de Neves e Spineli (2008), lê-se que os principais benefícios do estágio são para os estudantes, ficando pouco de ganho para a comunidade. Embora isso possa ser realidade, alguns ganhos para o local foram referidos direta ou indiretamente por estudantes e professores nesta pesquisa. O primeiro é sem dúvida o aumento e a qualificação da força de trabalho. São estudantes de medicina do último ano que fazem o estágio, podendo aumentar a capacidade de atendimento do serviço em que estagiam. Seu recente conhecimento teórico pode trazer benefícios na atualização do médico e da equipe local, "funcionando indiretamente como um programa de atualização e reciclagem para os médicos locais" (Barbosa, 1995, p.33) e aumentando, por consequência, a qualidade do atendimento. Esse aspecto pode também acontecer pela dinamização da estratégia de Telessaúde pelo estudante, que pode ter mais tempo para sua utilização, ajudando a equipe local a se comunicar com a central do programa. Ainda em sua atuação direta, os estudantes podem contribuir, e costumam fazê-lo, na organização e execução de atividades de educação em saúde, onde têm a oportunidade de trocar ideias com a população e atuar na promoção da saúde local.

Outros ganhos para o município, mais indiretos, estão na simples presença da universidade na localidade, o que pode contribuir de alguma forma para o desenvolvimento local, e na possibilidade de que algum dos estudantes volte para trabalhar como médico, o que não é difícil de acontecer se a experiência for positiva para o estudante.

\section{Considerações finais}

Essas são atividades relativamente novas no contexto da graduação em medicina no Brasil e têm mostrado uma perspectiva diferenciada de itinerário formativo, trazendo outras questões para o centro do processo reflexivo da prática médica, como a história e a cultura do povo local. O contexto do interior da Amazônia, como cenário de ensino e aprendizagem para os cursos de medicina, tem ajudado a dar esse enfoque regional para as escolas médicas do Norte do país, bem como aumentar o sentimento de pertença pela região, nem sempre presente no estudante de medicina.

A história da implantação do internato rural na Amazônia se mistura com os processos de integração e desenvolvimento regional, e a partir de exemplos de sucesso vem se multiplicando, alcançando número expressivo de municípios na região. Com o crescimento do número de 
cursos de medicina na Amazônia na última década e a consolidação do internato rural como atividade importante nos currículos de medicina, começam a se apresentar os desafios para que as experiências sejam efetivadas e sejam positivas na vida do estudante. O cenário atual revela que embora algumas experiências estejam consolidadas, várias outras ainda enfrentam dificuldades em sua implantação. Essas dificuldades são de naturezas diversas, chamando a atenção a logística para a viabilização dessa experiência e a supervisão local como principais obstáculos na construção das propostas nas universidades.

Para enfrentar esses desafios, de modo a incrementar os argumentos para sua realização, torna-se importante produzir conhecimento sobre as experiências de internato rural, seu significado, sua importância pedagógica e suas consequências na formação e no trabalho, com foco especial para a interiorização da profissão, bem como a troca de ideias entre os professores e estudantes que participaram ou viveram a experiência. Dessa forma, criam-se subsídios para que a história continue a ser contada, dando uma contribuição pequena em termos de tempo, mas grande em termos de pensamento reflexivo, para uma prática médica mais humanizada e centrada nas pessoas.

\section{NOTA}

${ }^{1}$ A fonte dos dados sobre o Projeto Saúde e Alegria constituiu-se de documentos coletados e conversas com pessoas envolvidas ao longo do trabalho de campo de Silveira (2014).

\section{REFERÊNCIAS}

ABREU, Mauro H.N.G. et al.

A experiência do Programa de Educação pelo Trabalho em Saúde da UFMG: o caso da interface saúde/ambiente. Educação, v.13, p.13-28. 2009.

AYRES, José Ricardo C.M.

Uma concepção hermenêutica de saúde. Physis: Revista de Saúde Coletiva, v.17, n.1, p.43-62. 2007.

BARBOSA, Helena F.

Formação médica e internato rural: em busca da identidade pedagógica de uma experiência. Dissertação (Mestrado) - Faculdade de Educação, Universidade Federal de Minas Gerais, Belo Horizonte. 1995.

BRASIL.

Ministério da Educação. Sistema de Informação E-mec. Disponível em: http://emec.mec.gov.br/. Acesso em: 13 jun. 2015. 2015.

BRASIL.

Ministério da Educação. Conselho Nacional de Educação. Diretrizes Curriculares Nacionais do curso de graduação em medicina. Resolução CNE/CNS n.3, 20 de junho de 2014. Brasília (DF): MEC/Câmara de Educação Superior do Conselho Nacional de Educação. 2014.

BRASIL.

Ministério da Saúde. Secretaria de Atenção à

Saúde. Departamento de Atenção Básica. Política
Nacional de Atenção Básica. Brasília: Ministério da Saúde. 2012.

BRASIL.

Casa Civil. Lei n.11.788, de 25 de setembro de 2008. Dispõe sobre o estágio de estudantes. 2008.

BRASIL.

Conselho Nacional de Secretários de Saúde. Sistema Único de Saúde/Conselho Nacional de Secretários de Saúde. Brasília: Conass. 2007.

BRASIL.

Ministério da Educação. Conselho Nacional de Educação. Diretrizes Curriculares Nacionais do curso de graduação em medicina. Resolução CNE/CNS n.4, 7 de novembro de 2001. Brasília (DF): MEC/Câmara de Educação Superior do Conselho Nacional de Educação. 2001.

BRASIL.

Ministério da Educação e Cultura. Uma visão do campus avançado pelo Conselho de Reitores das Universidades Brasileiras e Fundação Projeto Rondon. Brasília: MEC/DDD. 1980.

BRASIL.

Ministério da Educação e Cultura. O projeto Rondon. (Coleção Brasil Hoje, 9). Rio de Janeiro: Bloch. 1972. 
DEWEY, John.

Experiência e educação. Petrópolis: Vozes. 2010.

GUIMARÃES, Emanuel V.

O Internato Rural e a formação do profissional médico para o Programa de Saúde da Família. Dissertação (Mestrado em Saúde Pública). Belo Horizonte: Universidade Federal de Minas Gerais. 2004.

LIMA, Gabriel A.B.

A contestação, um fenômeno mundial, 1: movimento estudantil e ditadura civil-militar nos primeiros anos do Projeto Rondon (196769). Encontro Regional da Associação Nacional de História, 18, Seção Minas Gerais. Anais... Belo Horizonte. 2012.

MACIEL FILHO, Rômulo; BRANCO, Maria Alice F. Rumo ao interior: médicos, saúde da família e mercado de trabalho. Rio de Janeiro: Fiocruz. 2008.

NEVES, Marco Aurélio B.; SPINELLI, Maria Angélica.

Integração ensino-serviços de saúde: o internato rural médico da Universidade Federal de Mato Grosso. Trabalho, Educação e Saúde, v.6, n.2, p.341-366. 2008.

POLIGNANO, Marcus V. et al.

Internato Rural da Faculdade de Medicina da UFMG: 25 anos de integração docenteassistencial. In: Congresso Brasileiro de Extensão Universitária, 2., 2004, Belo Horizonte. (Re) conhecer diferenças, construir resultados, v.1, p.305-313. Brasília: Unesco. 2004.

ROURKE, James T.B. et al.

Relationship between practice location of Ontario family physicians and their rural background or amount of rural medical education experience. Canadian Journal of Rural Medicine, v.10, n.4, p.231-239. 2005.

SANTOS, Maria da Soledade S.; MENDES, Isabel A.C.

Projeto Rondon: a metodologia educativoassistencial de trabalho dos estagiários universitários. Escola Anna Nery Revista Enfermagem, v.9, n.1, p.124-137. 2005.
SILVA, José M.

A atual política de extensão da Universidade Federal Fluminense. Monografia (Especialização em Gestão Pública) - Faculdade Integrada AVM, Universidade Cândido Mendes, Rio de Janeiro. 2013.

SILVA, Roseli F.; FRANCISCO, Marcus António. Portfólio reflexivo: uma estratégia para a formação em Medicina. Revista Brasileira de Educação Médica, v.33, n.4, p.562-570. 2009.

SILVEIRA, Rodrigo P.

Itinerários formativos do Internato Rural na Amazônia: experiências nas fronteiras de mundo, saberes e práticas e responsabilidade. Tese (Doutorado em Saúde Coletiva) - Instituto de Medicina Social, Universidade do Estado do Rio de Janeiro, Rio de Janeiro. 2014.

SOARES, Angela C.P. et al.

A importância da regulamentação da preceptoria para a melhoria da qualidade dos programas de residência médica na Amazônia Ocidental. Cadernos da ABEM, v.9, p.14-22. 2013.

TARGA, Leonardo $\mathrm{V}$.

Mobilizando coletivos e construindo competências culturais no cuidado à saúde - estudo antropológico da política brasileira de Atenção Primária à Saúde. Dissertação (Mestrado em Antropologia Social) - Instituto de Filosofia e Ciências Humanas, Universidade Federal do Rio Grande do Sul, Porto Alegre. 2010.

TESSON, Geoffrey et al.

Advances in rural medical education in three countries: Canada, The United States and Australia. Rural and Remote Health, v.5, n.4, p.397-404. 2005.

UEG.

Universidade do Estado da Guanabara. Ato executivo n.229, de 8 dezembro de 1969. Fica estabelecida, em caráter experimental, na cidade de Parintins... 8 dez. 1969.

UNIVERSIDADE DO AMAZONAS.

Conselho de Ensino e Pesquisa, Resolução n.018/1991, regulamenta o internato do curso de medicina. 1991. 